\title{
Metastatic Adenoid Cystic Carcinoma
}

National Cancer Institute

\section{Source}

National Cancer Institute. Metastatic Adenoid Cystic Carcinoma. NCI Thesaurus. Code C157638.

An adenoid cystic carcinoma that has spread from the original site of growth to other anatomic sites. 